\title{
Inhibition of Cortical Collecting Tubule Chloride Transport by Organic Acids
}

\author{
Kenzo Matsuzaki, John B. Stokes, and Victor L. Schuster \\ Laboratory of Epithelial Transport, University of Iowa, and Veterans Administration Medical Center, Iowa City, Iowa 52242
}

\begin{abstract}
Cl self-exchange by the rabbit cortical collecting tubule (CCT) occurs via an apical anion exchanger in series with a basolateral $\mathrm{Cl}$ conductance. We studied the effects of organic acids on CCT Cl self-exchange. We found no evidence for transport of acid anions by the self-exchange system. Rather, $\mathrm{Cl}$ self-exchange was inhibited by a variety of organic acids. The degree of inhibition correlated with the chloroform/water partition coefficient and was enhanced by lowering $\mathrm{pH}$, indicating inhibition by the lipid-soluble, protonated species. Inhibition by the representative acid iso-butyrate was dose-dependent and showed sidedness (basolateral $>$ apical). Iso-butyrate also reversibly reduced transepithelial conductance without altering $K$ permeability, suggesting inhibition of the principal cell basolateral $\mathrm{Cl}$ conductance. Because small organic compounds with similar lipid solubilities but no carboxyl group had no effect, both the carboxyl group and the lipid-solubility of organic acids appear to be important. The results are consistent with blockade of chloride channels by organic acids.
\end{abstract}

\section{Introduction}

The transcellular transfer of $\mathrm{Cl}$ across the cortical collecting tubule $(\mathrm{CCT})^{1}$ occurs through a population of intercalated cells specialized for $\mathrm{HCO}_{3}$ secretion. These cells, called $\beta$ intercalated cells (1), have an anion exchanger on their apical (luminal) membrane and a $\mathrm{Cl}$ conductive pathway (channel) on the basolateral membrane. Although this transepithelial anion exchange process secretes $\mathrm{HCO}_{3}$, the system operates more often in a $\mathrm{Cl}$ self exchange mode. In the absence of exogenous $\mathrm{CO}_{2}$ and $\mathrm{HCO}_{3}$, transcellular $\mathrm{Cl}$ transport occurs exclusively by self-exchange $(2,3)$.

In order to understand this transepithelial anion exchange system more completely, we investigated the effects of organic anions on $\mathrm{Cl}$ transport. We anticipated two general outcomes. First, organic anions could have been transported as substrates as is the case for some organic anions transported on the red cell band 3 exchanger (4). Precedence for transepithelial organic anion transport can be found in the proximal renal tu-

\footnotetext{
Address reprint requests to Dr. Schuster, Department of Internal Medicine, University of lowa, Iowa City, IA 52242.

Received for publication 20 August 1987 and in revised form 2 December 1987.

1. Abbreviations used in this paper: CCT, cortical collecting tubule; CVT, calibrated volume pipette; GABA, $\gamma$-amino butyric acid; $G_{\mathrm{T}}$, transepithelial conductance; $J_{\mathrm{v}}$, net volume reabsorption; MAPTAM, 1,2-bis-5-methyl-amino-phenoxylethane- $N, N, N^{\prime}$-tetraacetoxymethyl acetate.
}

The Journal of Clinical Investigation, Inc.

Volume 82 , July $1988,57-64$ bule, in which organic acids absorbed via a luminal membrane $\mathrm{Na}$ (lactate) cotransporter (5) exit the basolateral membrane via a conductive pathway (6). Additional examples of epithelial organic acid transport can be found in the gallbladder (7) and small intestine (8). Because these transport systems involve anion exchangers, we reasoned that there may be similarities with the CCT anion transport system.

Second, we recognized that organic acids might inhibit transepithelial anion exchange. Organic acids have been shown to inhibit membrane conductive pathways (9-12) and might not substitute on all anion exchangers. We had a special a priori interest in the effect of two organic anions on CCT $\mathrm{Cl}$ transport: lactate, by virtue of its being perhaps the most abundant organic anion, and formate, an anion which stimulates $\mathrm{Cl}$ transport in the proximal tubule (13) and which may have a major role in volume absorption $(14,15)$.

The results of our experiments provide no evidence for significant transport of organic acids; rather they demonstrate one mechanism whereby organic acids can inhibit $\mathrm{Cl}$ transport systems.

\section{Methods}

General microperfusion methods. Segments of rabbit cortical collecting tubule were perfused in vitro by techniques previously described $(9$, 16). Briefly, New Zealand white rabbits weighing $1.5-2.5 \mathrm{~kg}$ were given free access to water and standard rabbit chow. After decapitation, the left kidney was quickly removed and cut into $1-2-\mathrm{mm}$ thick coronal slices. Cortical collecting tubules were dissected at $0-4^{\circ} \mathrm{C}$, transferred to a Lucite chamber thermally regulated at $37 \pm 0.5^{\circ} \mathrm{C}$, and mounted in glass pipettes at both ends. The perfusion pipette served as a voltagesensing electrode for transepithelial voltage $\left(V_{\mathrm{T}}\right)$ measurements and also as a pathway for injected current for transepithelial conductance $\left(G_{T}\right)$ measurements (9). Perfusate and control bath solutions contained: $105 \mathrm{mM} \mathrm{NaCl}, 25 \mathrm{mM}$ Na-gluconate, $5 \mathrm{mM} \mathrm{Na}$-Hepes, $5 \mathrm{mM}$ $\mathrm{H}$-Hepes, $5 \mathrm{mM} \mathrm{KCl}, 2.3 \mathrm{mM} \mathrm{Na} \mathrm{HPO}_{4}, 1.0 \mathrm{mM} \mathrm{MgCl}, 3.3 \mathrm{mM}$ $\mathrm{CaCl}_{2}$, and $8.3 \mathrm{mM}$ dextrose. In experiments in which the effects of various organic acids on lumen-to-bath tracer fluxes were examined, the concentration of Na-gluconate was reduced by the concentration of these organic acids used. When $\mathrm{Cl}$ was removed from the bath solution, gluconate was substituted. The concentration of calcium salts was appropriately adjusted to keep the ionized $\mathrm{Ca}$ concentration at $1.0 \mathrm{mM}$ in every solution according to the gluconate concentration used (17).

The $\mathrm{pH}$ of perfusate and bath solutions was 7.37-7.42 after gassing with $100 \% \mathrm{O}_{2}$. For bath solutions of $\mathrm{pH} 7.0$, the ratio of $\mathrm{Na}-\mathrm{Hepes}$ and $\mathrm{H}$-Hepes was adjusted appropriately. All perfusates contained $50 \mu \mathrm{M}$ amiloride in order to eliminate active $\mathrm{Na}$ and $\mathrm{K}$ transport and minimize the electrical driving force for $\mathrm{Cl}$ diffusion (2). All bath solutions (except in experiments involving ${ }^{86} \mathrm{Rb}$ flux measurements) contained $0.1 \mathrm{mM}$ 8-bromo-cAMP to avoid the time-dependent decrement of $\mathrm{Cl}$ transport (2).

Tracer flux measurements. Three kinds of tracer flux measurements were performed using ${ }^{36} \mathrm{Cl},{ }^{86} \mathrm{Rb}$, and $\left[{ }^{14} \mathrm{C}\right]$ iso-butyrate. All perfusates contained exhaustively dialyzed methoxy- $\left[{ }^{3} \mathrm{H}\right]$ inulin as a vol-

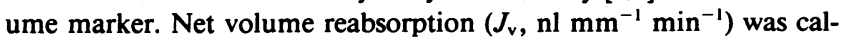
culated as previously described (18). Experiments in which $J_{\mathrm{v}}$ were more than $\pm 0.1 \mathrm{nl} \mathrm{mm} m^{-1} \mathrm{~min}^{-1}$ were discarded. 
${ }^{86} \mathrm{Rb}$ flux measurements were performed and expressed as the rate coefficient $\left(K_{\mathrm{Rb}}, \mathrm{nm} \mathrm{s}^{-1}\right)$ as previously described (19). In these experiments tubules were perfused at slow rates $\left(3-7 \mathrm{nl} \mathrm{min}^{-1}\right)$. Lumen-tobath ${ }^{86} \mathrm{Rb}$ fluxes were determined from the difference in ${ }^{86} \mathrm{Rb}$ counts between the perfusate and the fluids collected in a calibrated volume pipette (CVP).

${ }^{36} \mathrm{Cl}$ flux measurements were performed by both CVP and bath collection methods. In the case of bath collection, tubules were perfused at rapid rates $\left(>20 \mathrm{nl} \mathrm{min}{ }^{-1}\right)$. Lumen-to-bath ${ }^{36} \mathrm{Cl}$ fluxes were determined from ${ }^{36} \mathrm{Cl}$ counts in timed collections $(5 \mathrm{~min})$ of bath fluid and the $\mathrm{Cl}$ rate coefficient $\left(K_{\mathrm{Cl}}, \mathrm{nm} \mathrm{s}{ }^{-1}\right)$ was calculated using the following expression: $K_{\mathrm{Cl}}=C_{\mathrm{b}} / C_{\mathrm{o}}^{*} A t$ where $C_{\mathrm{b}}$ is the counts appearing in the bath over time $t, C_{0}^{*}$ is the concentration of tracer in the perfused fluid, and $A$ the area of the tubule calculated from the inner diameter. Both ends of the tubule were tightly sealed with unpolymerized Sylgard (Dow Corning Corp., Midland, MI) to avoid leakage of the perfusate into the bath. Experiments in which $>1 \%$ of perfused $\left[{ }^{3} \mathrm{H}\right]$ inulin counts appeared in the collected bath fluid were discarded. As a further check on the accuracy of the bath vs. the CVP collection methods, we compared the $\mathrm{K}_{\mathrm{Cl}}$ values in tubules where $\mathrm{Cl}-\mathrm{Cl}$ and $\mathrm{Cl}-\mathrm{HCO}_{3}$ exchange had been eliminated by removing $\mathrm{Cl}$ and $\mathrm{HCO}_{3}$ from the bath $(2,3)$. The low value of $K_{C l}$ obtained under these conditions increases the probability of uncovering a technical artifact. $\mathrm{K}_{\mathrm{Cl}}$ values were $26.4 \pm 2.3 \mathrm{~nm} \mathrm{~s}^{-1}(n=11)$ by the CVP collection method and $30.7 \pm 2.6$ $\mathrm{nm} \mathrm{s}^{-1}(n=19)$ by bath collection method (NS, unpaired $t$ test). We conclude that either method will provide an accurate estimate of the lumen-to-bath tracer flux.

In many experiments the data are expressed in terms of $\mathrm{Cl}$ self exchange. We have previously shown (2) that, under the present experimental conditions, the $\mathrm{Cl}$ self-exchange rate is the difference between $\mathrm{K}_{\mathrm{Cl}}$ in the presence and absence of bath $\mathrm{Cl}$. This method was used in the present protocols: the last experimental period was one in which bath $\mathrm{Cl}$ was removed (gluconate replacement) and $\mathrm{K}_{\mathrm{Cl}}$ measured. This

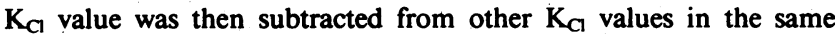
experiment to obtain $\mathrm{Cl}$ self-exchange rates.

For $\left[{ }^{14} \mathrm{C}\right]$ iso-butyrate flux measurements, tubules were perfused at rapid rates $\left(>20 \mathrm{nl} \mathrm{min}^{-1}\right)$ and both CVP and bath collections were made. CVP collection was used to compare the counts of $\left[{ }^{14} \mathrm{C}\right]$ isobutyrate between the perfusate and the collected fluid. The rate coefficient for $\left[{ }^{14} \mathrm{C}\right]$ iso-butyrate was obtained by the bath collection method.

Transepithelial conductance measurements. The transepithelia conductance $\left(G_{\mathrm{T}}\right)$ was measured by techniques previously described (9). Constant-current square-wave pulses (40-75 nA, $100 \mathrm{~ms}$ duration) were injected into the tubule lumen via the perfusion pipette. An electrical bridge was balanced for the particular perfusate used, thus allowing voltage deflections at the perfusion pipette to be nulled in the absence of a tubule. Voltage deflections at the distal end of the tubule were measured by a $\mathrm{Ag}-\mathrm{AgCl}$ electrode placed in a microelectrode filled with $3 \mathrm{M} \mathrm{KCl}$ in agar. The $G_{\mathrm{T}}\left(\mathrm{mS} \mathrm{cm}^{-2}\right)$ was calculated using cable analysis as previously described from our laboratory (9).

Partition coefficients. Partition coefficients in chloroform/aqueous phase systems $\left(\mathrm{K}_{\mathrm{p}}^{\text {chloro }}\right)$ were determined for nonionic forms of several organic acids, and in olive oil/aqueous and ether/aqueous for iso-butyrate using a modified radiotracer method previously described (20). In general, $1 \mathrm{ml}$ of aqueous solution, $\mathrm{pH} 1.5$ containing $0.03-0.07 \mu \mathrm{Ci}$ of ${ }^{14} \mathrm{C}$-labeled organic acids was mechanically shaken with $3 \mathrm{ml}$ of nonaqueous phase solution for $\mathrm{i} \mathrm{h}$ at room temperature. After centrifugation for $15 \mathrm{~min}$ at $1,500 \mathrm{~g}$, samples were carefully taken from both phases and counted in 3a70 cocktail (Research Products Corp., Mt. Prospect, IL). ${ }^{14} \mathrm{C}$ counts per minute were converted to disintegrations per minute using measured counting efficiencies in water and the nonaqueous phase liquid. Partition coefficients $\left(\mathrm{K}_{\mathrm{p}}\right)$ for undissociated forms of organic acids were calculated according to formulae previously described (20); the calculations shown below use the example of the chloroform/aqueous partition coefficient: $\mathrm{K}_{\mathrm{p}}^{\text {chloro }}=r\left(1+10^{\alpha}\right)$, where $r={ }^{14} \mathrm{C}(\mathrm{dpm}) / \mathrm{ml}$ in chloroform phase $/{ }^{14} \mathrm{C}(\mathrm{dpm}) / \mathrm{ml}$ in aqueous phase, and $\alpha=\mathrm{pH}$ (aqueous phase) - pKa. pKa is the dissociation constant for the organic acid being examined.

Reagents and isotopes. 8-Bromo-cyclic adenosine 3'5'-monophosphate (8-Br-cAMP), formate, $\mathrm{L}(+)$-lactate, $n$-valerate, $n$-butyrate, propionate, caprylate, benzoate, $\gamma$-amino butyric acid (GABA), and naloxone were purchased from Sigma Chemical Co. (St. Louis, MO). Acetate and iso-butyrate were purchased from Fisher Scientific Co. (Fair Lawn, NJ). 1,2-bis-5-methyl-aminophenoxylethane- $N, N, N$-tetraacetoxymethyl acetate (MAPTAM) was purchased from Calbiochem-Behring (La Jolla, CA). Amiloride was a gift of the Merck, Sharp and Dohme Division (West Point, PA). Methoxy- $\left[{ }^{3} \mathrm{H}\right]$ inulin, ${ }^{36} \mathrm{Cl}$, ${ }^{86} \mathrm{Rb},\left[{ }^{14} \mathrm{C}\right]$ iso-butyrate, $\left[{ }^{14} \mathrm{C}\right]$ acetate, $\left[{ }^{14} \mathrm{C}\right]$ formate, and $\left[{ }^{14} \mathrm{C}\right]$ lactate were purchased from New England Nuclear (Boston, MA).

Statistics. Statistical analyses were performed by paired and unpaired $t$ test or ANOVA as appropriate. If ANOVA showed a significant difference between groups, the studentized range test was used to examine for differences between individual groups. Results are expressed as means $\pm \mathrm{SE}$.

\section{Results}

Effect of bath iso-butyrate on $K_{C l}$. We first examined the effect of bath iso-butyrate on the ${ }^{36} \mathrm{Cl}$ lumen-to-bath tracer rate coefficient $\left(\mathrm{K}_{\mathrm{C}}\right)$. As shown in Fig. 1, $25 \mathrm{mM}$ bath iso-butyrate reversibly reduced $\mathrm{K}_{\mathrm{Cl}}$ from $141.0 \pm 17.0$ to $33.4 \pm 7.3 \mathrm{~nm} \mathrm{~s}^{-1}$ $\left(\Delta \mathrm{K}_{\mathrm{Cl}}=-107.6 \pm 14.7 \mathrm{~nm} \mathrm{~s}^{-1}, P<0.001\right)$. Given the limited temporal resolution of flux studies, the onset of action appeared to occur in less than $15 \mathrm{~min}$ and recovery occurred within $30 \mathrm{~min}$. Table I shows the dose-response of the bath iso-butyrate effect on $\mathrm{K}_{\mathrm{Cl}}$. Four concentrations of iso-butyrate $(1,2.5,10$, and $25 \mathrm{mM})$ were sequentially examined in this order in each experiment. At a concentration of $25 \mathrm{mM}$, isobutyrate produced a reduction of $\mathrm{K}_{\mathrm{C}}$ not different from the value obtained with a $\mathrm{Cl}$-free bath solution. Because $\mathrm{K}_{\mathrm{Cl}}$ values in the $\mathrm{Cl}$-free period most likely reflect paracellular $\mathrm{Cl}$ diffusion $(2,9)$, the differences between $\mathrm{K}_{\mathrm{Cl}}$ values in each period and that of the $\mathrm{Cl}$-free period are reasonable estimates of $\mathrm{Cl}$ self-exchange. The fractional inhibition of $\mathrm{Cl}$ self exchange by each dose of iso-butyrate was calculated in this fashion and the results plotted in Fig. $2 A$. Fig. $2 B$ demonstrates a double reciprocal plot of the data in Fig. $2 A$. The $\mathrm{IC}_{50}$ from this double reciprocal plot was $2.3 \mathrm{mM}$. From this value the doseresponse curve in Fig. $2 A$ was drawn.

Rank order inhibitory potency of organic acids on $\mathrm{Cl}$ selfexchange. We compared the effect of iso-butyrate on $\mathrm{Cl}$ selfexchange with the effects of eight other organic acids: formate, acetate, $\mathrm{L}(+)$-lactate, $n$-butyrate, propionate, $n$-valerate, caprylate, and benzoate. These organic acids were examined sequentially and in random order in two separate groups of

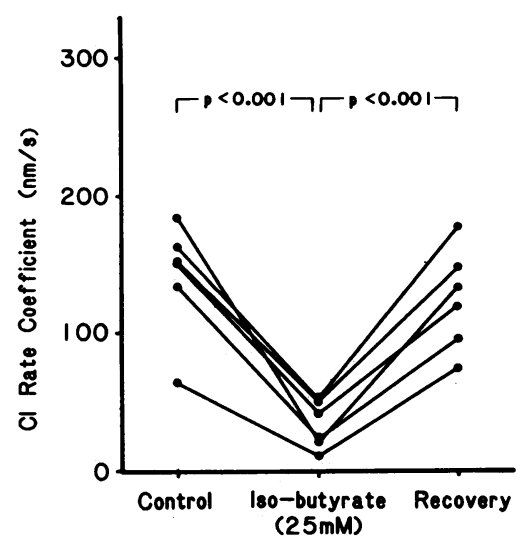

$(25 \mathrm{mM})$
Figure 1. Effect of bath iso-butyrate on lumento-bath ${ }^{36} \mathrm{Cl}$ tracer rate coefficient. Mean decrement was $107.6 \pm 14.7$ $\mathrm{nm} \mathrm{s}^{-1}$. 
Table I. Dose Response of Bath Iso-Butyrate Effect on the Cl Efflux Rate Coefficient $\left(K_{C l}\right)$

\begin{tabular}{|c|c|c|c|c|c|c|}
\hline & \multirow[b]{2}{*}{ Control* } & \multicolumn{4}{|c|}{ Iso-butyrate concentration } & \multirow[b]{2}{*}{$0 \mathrm{Cl}^{*}$} \\
\hline & & $1 \mathrm{mM}$ & $2.5 \mathrm{mM}$ & $10 \mathrm{mM}$ & $25 \mathrm{mM}$ & \\
\hline $\mathrm{K}_{\mathrm{c}}, \mathrm{nm} \mathrm{s}^{-1}$ & 132.8 & 100.7 & 84.2 & 44.9 & 31.3 & 29.4 \\
\hline$(n=5)$ & \pm 8.5 & \pm 8.8 & \pm 7.5 & \pm 3.9 & \pm 3.5 & \pm 4.7 \\
\hline
\end{tabular}

* Iso-butyrate concentration $=0 \mathrm{mM}$.

experiments; their concentrations were all $10 \mathrm{mM}$ (bath side). All experiments included a control period as well as iso-butyrate and $\mathrm{Cl}$-free periods. Fractional inhibition of $\mathrm{Cl}$ self-exchange for each organic acid was calculated by subtracting the $\mathrm{K}_{\mathrm{Cl}}$ in the $0 \mathrm{Cl}$ period from the values obtained in the previous periods. As shown in Table II, all but formate showed significant inhibitory effects on $\mathrm{Cl}$ self-exchange. Caprylate was the most potent of the organic acids examined. Among the other aliphatic compounds, iso-butyrate, proprionate, $n$-butyrate, and $n$-valerate demonstrated similar potencies.

pH influence on iso-butyrate inhibition of Cl self-exchange. To determine whether the $\mathrm{pH}$ of iso-butyrate-containing bath solutions might influence the ability of iso-butyrate to inhibit $\mathrm{Cl}$ self-exchange, we compared the inhibitory effect of $3 \mathrm{mM}$ iso-butyrate bath solutions at $\mathrm{pH} 7.0$ and at $\mathrm{pH}$ 7.4. Based on a pKa of 4.85 (21), the calculated concentrations of (undissociated) iso-butyric acid in these two solutions were $22.1 \mu \mathrm{M}$ at pH 7.0 and $9.0 \mu \mathrm{M}$ at $\mathrm{pH}$ 7.4. We previously showed (3) that varying the $\mathrm{pH}$ of Hepes-buffered bath solutions over the range of 7.0 to 7.4 itself had no effect on $\mathrm{K}_{\mathrm{Cl}}$. Therefore, any difference in the inhibitory effects of $3 \mathrm{mM}$ iso-butyrate on $\mathrm{Cl}$ self-exchange as a function of bath $\mathrm{pH}$ could be reasonably attributed to a difference in the concentration of (undissociated) iso-butyric acid. The experiments were conducted in four periods, the first and last being the control and the $0 \mathrm{Cl}$ bath periods, respectively. The sequence of iso-butyrate expo-
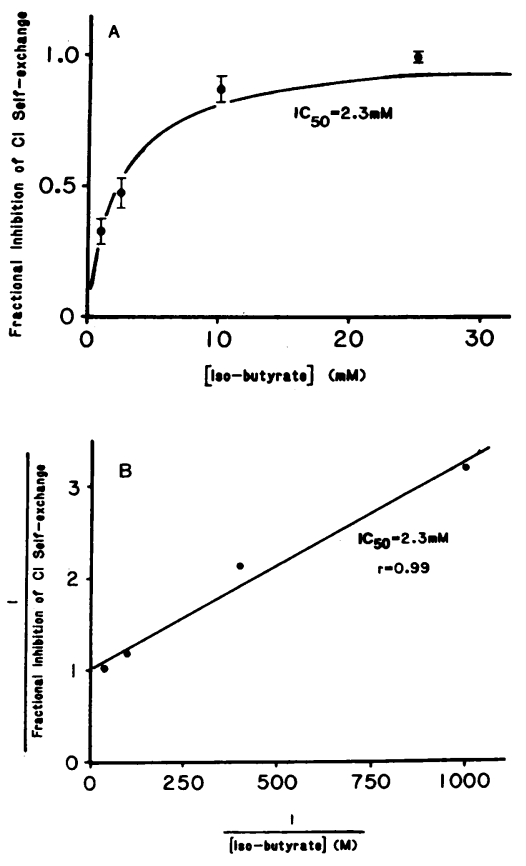

Figure 2. (A) Fractional inhibition of $\mathrm{Cl}$ self-exchange by iso-butyrate. $\mathrm{Cl}$ self-exchange values were calculated by subtracting the value of $\mathrm{K}_{\mathrm{C}}$ in a Cl-free bath from those obtained at each iso-butyrate concentration. (B) Double reciprocal plot of the data in A. IC 50 of $2.3 \mathrm{mM}$ was used to generate the curve in A. $n=5$.
Table II. Chloroform/Water Partition Coefficients ( $K_{p}^{\text {chloro }}$ ) and Fractional Inhibition of Cl Self-exchange by Organic Acids

\begin{tabular}{lcccc}
\hline Organic acid & $\begin{array}{c}\text { Fractional inhibition } \\
\text { of Cl self-exchange }\end{array}$ & $n$ & $\mathrm{~K}_{\mathrm{p}}^{\text {chloro }}$ & $\mathrm{pKa}$ \\
\hline & $\%$ & & & \\
Formate & $6.3 \pm 3.0$ & 5 & $7.9 \times 10^{-3 *}$ & 3.75 \\
Acetate & $30.0 \pm 4.9$ & 5 & $2.5 \times 10^{-2}$ & 4.76 \\
& & & $3.2 \times 10^{-2 *}$ & \\
L(+)-Lactate & $38.1 \pm 7.5$ & 5 & $4.0 \times 10^{-3 *}$ & 3.86 \\
$n$-Valerate & $51.6 \pm 5.9$ & 5 & $7.9 \times 10^{-1}$ & 4.84 \\
$n$-Butyrate & $64.6 \pm 6.5$ & 5 & $5.0 \times 10^{-1}$ & 4.83 \\
Propionate & $68.7 \pm 4.5$ & 5 & $1.6 \times 10^{-1}$ & 4.87 \\
Iso-butyrate & $72.7 \pm 4.0$ & 10 & $6.3 \times 10^{-1}$ & 4.85 \\
& & & $6.3 \times 10^{-1 *}$ & \\
Benzoate & $89.5 \pm 1.4$ & 5 & 3.2 & 4.21 \\
Caprylate & $93.8 \pm 2.7$ & 5 & 25.1 & 4.90
\end{tabular}

* Measured values. Other $\mathrm{K}_{\mathrm{p}}^{\text {chloro }}$ values taken from ref. 20.

$n=$ number of tubules. pKa values from reference 5 . All concentrations $=10 \mathrm{mM}, \mathrm{pH} 7.4$.

sure at the different $\mathrm{pH}$ values was randomized. As shown in Table III, iso-butyrate at a $\mathrm{pH}$ of 6.98 was more effective at inhibiting $\mathrm{K}_{\mathrm{Cl}}$ than at 7.37. The mean paired difference in the $\mathrm{K}_{\mathrm{C}}$ values for these solutions was $27.0 \pm 6.6 \mathrm{~nm} \mathrm{~s}^{-1}(P<0.02)$. Fig. 3 shows the fractional inhibition of $\mathrm{Cl}$ self-exchange as a function of the calculated (undissociated) iso-butyric acid concentration $(\mu \mathrm{M})$ in these experiments. The solid line depicts the dose-response relationship predicted from the data of Table I and Fig. $2 A$, expressed in terms of (undissociated) iso-butyric acid concentration rather than butyrate. The fractional inhibition of $\mathrm{Cl}$ self-exchange in the $\mathrm{pH}$-shift experiments was not significantly different from the predicted values. These results indicate that iso-butyrate's ability to inhibit $\mathrm{Cl}$ self-exchange is influenced by the $\mathrm{pH}$ in a manner consistent with inhibition by the undissociated form.

Partition coefficients, $\mathrm{pKa}$, and fractional inhibition of $\mathrm{Cl}$ self-exchange. Having demonstrated that the concentration of (undissociated) iso-butyric acid is important for inhibition of $\mathrm{Cl}$ self-exchange, we next examined the relationship between the partition coefficients of undissociated forms of organic acids and their abilities to inhibit $\mathrm{Cl}$ self-exchange.

Chloroform/water partition coefficients for many undisso-

Table III. Bath Iso-Butyrate Effect on Cl Self-exchange as a Function of $\mathrm{pH}$

\begin{tabular}{|c|c|c|c|c|}
\hline & Control & IB $3 \mathrm{mM}$ & IB $3 \mathrm{mM}$ & $0 \mathrm{Cl}$ \\
\hline & $\begin{array}{c}\mathrm{pH} 7.36 \\
\pm .008\end{array}$ & $\begin{array}{c}\mathrm{pH} 7.37 \\
\pm .014\end{array}$ & $\begin{array}{c}\mathrm{pH} 6.98 \\
\pm .016\end{array}$ & $\begin{array}{c}\mathrm{pH} 7.42 \\
\pm .015\end{array}$ \\
\hline $\mathrm{K}_{\mathrm{Cl}}, \mathrm{nm} \mathrm{s}^{-1}$ & 183.4 & 111.2 & 84.2 & 28.4 \\
\hline$(n=5)$ & \pm 13.6 & \pm 17.3 & \pm 14.7 & \pm 4.9 \\
\hline Fractional inhibition of & & 48.3 & 65.7 & \\
\hline $\mathrm{Cl}$ self-exchange $(\%)$ & & \pm 8.3 & \pm 6.9 & \\
\hline$P$ & \multicolumn{4}{|c|}{$<0.02$} \\
\hline
\end{tabular}

$\mathrm{K}_{\mathrm{Cl}}$, lumen-to-bath $\mathrm{Cl}$ rate coefficient; IB, iso-butyrate. $P$ value compares the IB periods. 


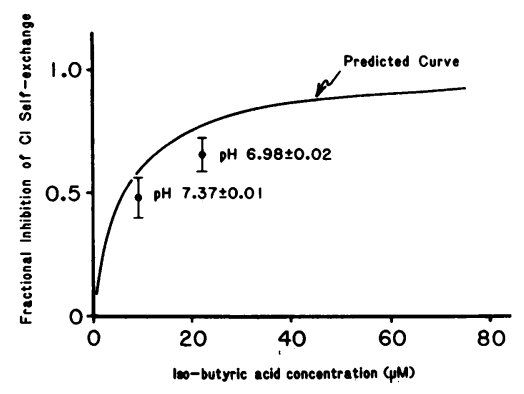

Figure 3. Influence of hibition of $\mathrm{Cl}$ self-exchange. The curve is presented in Fig. 2 but displayed as a function of (undissociated) isobutyric acid rather than the ionized form. The two points are from the data in Table III and are not different from the values predicted from the curve. $\mathrm{pH}$ on iso-butyrate indrawn from the data

ciated organic acids and bases $\left(\mathrm{K}_{\mathrm{p}}^{\text {chloro }}\right)$ have been previously determined by Jackson et al. (20). Using the methods they described, we determined partition coefficient values for several organic acids whose values were not available (Table II). Fig. 4 shows that there is a good correlation between fractional inhibition of $\mathrm{Cl}$ self-exchange by organic acids and their log $\mathrm{K}_{\mathrm{p}}^{\text {chloro }}(r=0.90, P<0.002)$. These results suggest that the lipid solubility of organic acids determines their potency in inhibiting $\mathrm{Cl}$ self-exchange.

Table II also shows the pKa of the organic acids examined. Unlike the situation with chloroform-water partition coefficients, the correlation between the $\mathrm{pKa}$ and the fractional inhibition of $\mathrm{Cl}$ self-exchange is poor $(r=0.549$, NS).

Effect of naloxone, $n$-butanol, and $G A B A$ on $K_{C l}$. It is conceivable that the undissociated forms of organic acids inhibit $\mathrm{K}_{\mathrm{Cl}}$ by interacting with the cell membrane as uncharged molecules by creating a more disordered lipid domain. To determine whether the inhibitory effect of these compounds on $\mathrm{Cl}$ self-exchange is specific for organic acids, we first examined the effect of naloxone on $\mathrm{K}_{\mathrm{Cl}}$. Naloxone is an organic base, but its $\mathrm{K}_{\mathrm{p}}^{\text {chloro }}$ is reasonably close to that of iso-butyrate (about 2.0 $\left.\times 10^{-1}\right)(20)$. As shown in Table IV, $1 \mathrm{mM}$ naloxone had no effect on $\mathrm{K}_{\mathrm{Cl}}$. It should be noted that, based on the naloxone $\mathrm{pK}_{\mathrm{b}}$ of 6.93 , the calculated concentration of the undissociated form of naloxone in these experiments is $662 \mu \mathrm{M}$. In contrast, the calculated undissociated concentration of iso-butyric acid is $27 \mu \mathrm{M}$ at $10 \mathrm{mM}$ total iso-butyrate ( $\mathrm{pH} 7.4)$. Viewed from

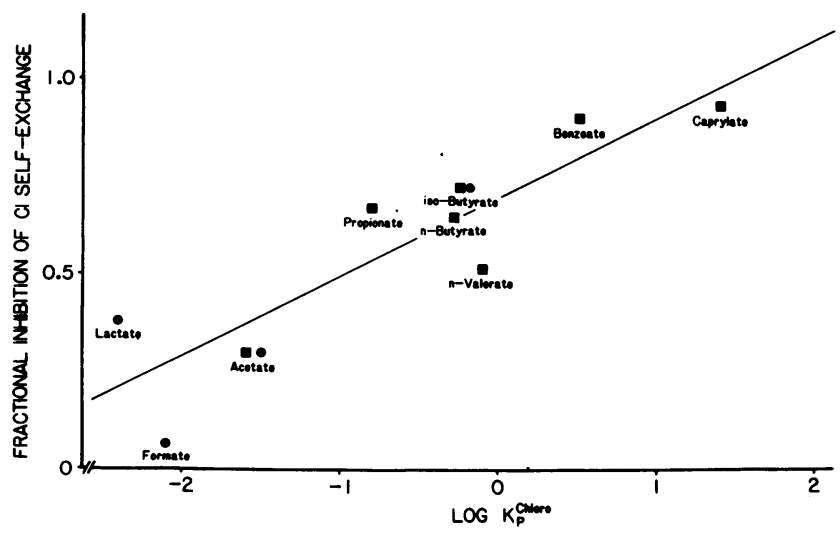

Figure 4. Fractional inhibition of $\mathrm{Cl}$ self-exchange as a function of the chloroform:water partition coefficient ( $\mathrm{K}_{\mathrm{p}}^{\text {chloro }}, \log$ scale). Squares represent $\mathrm{K}_{\mathrm{p}}^{\text {chloro }}$ values determined by Jackson et al. (20), circles represent values determined by us.
Table IV. Effect of Naloxone, n-Butanol, GABA, MAPTAM, and Cyanide on $K_{C l}$

\begin{tabular}{|c|c|c|c|c|c|}
\hline \multirow[b]{2}{*}{ Agent } & \multirow[b]{2}{*}{$n$} & Control & Experimental & \multirow{2}{*}{$\begin{array}{l}\text { Mean paired } \\
\text { difference }\end{array}$} & \multirow[b]{2}{*}{$P$} \\
\hline & & \multicolumn{2}{|c|}{$\mathrm{K}_{\mathrm{a}}, \mathrm{nm} \mathrm{s}^{-1}$} & & \\
\hline & & 208.6 & 215.2 & 6.6 & \\
\hline Naloxone $1 \mathrm{mM}$ & 5 & \pm 52.2 & \pm 57.3 & \pm 17.0 & NS \\
\hline & & 296.4 & 300.4 & 3.9 & \\
\hline$n$-Butanol $1 \mathrm{mM}$ & 7 & \pm 34.4 & \pm 32.4 & \pm 9.6 & NS \\
\hline & & 185.2 & 187.0 & 1.8 & \\
\hline GABA $10 \mathrm{mM}$ & 5 & \pm 49.0 & \pm 47.3 & \pm 5.5 & NS \\
\hline & & 179.7 & 185.7 & 6.1 & \\
\hline MAPTAM $0.1 \mathrm{mM}$ & 4 & \pm 26.9 & \pm 28.4 & \pm 8.4 & NS \\
\hline & & 376.2 & 299.9 & -76.4 & \\
\hline Cyanide $1 \mathrm{mM}$ & 5 & \pm 55.1 & \pm 46.0 & \pm 15.0 & $<0.01$ \\
\hline
\end{tabular}

Agents were added to bath solution.

this perspective of lipid solubility, it is clear that no effect on $\mathrm{K}_{\mathrm{Cl}}$ is produced by naloxone at a concentration 25 times higher than that concentration of iso-butyric acid causing a $70-80 \%$ inhibition of self-exchange.

Table IV also shows the effect of the alcohol of butyric acid, $n$-butanol, on $\mathrm{K}_{\mathrm{Cl}} .1 \mathrm{mM} n$-butanol had no effect on $\mathrm{K}_{\mathrm{Cl}}$. We estimated $\mathrm{K}_{\mathrm{p}}^{\text {chloro }}$ for $n$-butanol as follows. We used published values of $\mathrm{K}_{\mathrm{p}}^{\text {olive oil }}$ and $\mathrm{K}_{\mathrm{p}}^{\text {ether }}$ for $n$-butanol (22). We assumed that the ratio of partition coefficients determined in two different oil/water systems is the same for all organic compounds. That is, $\mathbf{K}_{\mathbf{p}}^{\text {chloro }} / \mathbf{K}_{\mathrm{p}}^{\text {ether }}$ for iso-butyrate should equal $\mathbf{K}_{\mathbf{p}}^{\text {chloro }}: K_{\mathbf{P}}^{\text {ether }}$ for $n$-butanol. Therefore, we measured $\mathrm{K}_{\mathrm{p}}^{\text {chloro }}$ and $\mathrm{K}_{\mathrm{p}}^{\text {ether }}$ for iso-butyrate and used the published value for $\mathrm{K}_{\mathrm{p}}^{\text {ether }}$ of $n$-butanol to derive a $\mathrm{K}_{\mathrm{p}}^{\text {chloro }}$ for $n$-butanol of $6.3 \times 10^{-1}$. An identical value was obtained using the ratio $\mathrm{K}_{\mathrm{p}}^{\text {chloro }} / \mathrm{K}_{\mathrm{p}}^{\text {olive oil }}$. This value of $\mathrm{K}_{\mathrm{p}}^{\text {chloro }}$ for $n$-butanol is identical to that for iso-butyrate and similar to that for $n$-butyrate $\left(5.0 \times 10^{-1}\right.$, Table II). Thus, at the same extracellular concentrations, $n$-butanol and isobutyric acid would produce the same concentration in the membrane. Nonetheless, $1,000 \mu \mathrm{M}$ of $n$-butanol had no effect on $\mathrm{K}_{\mathrm{Cl}}$, whereas $27 \mu \mathrm{M}$ of the equally lipid-soluble $n$-butyric acid inhibited $\mathrm{K}_{\mathrm{Cl}}$ by $65 \%$ (Table II). We interpret these results with naloxone and $n$-butanol as indicating that the effect of the organic acids is not related solely to their lipid solubility, but is also dependent on the presence of the carboxyl group in the organic acid.

We also considered that these organic acids may be interacting with a regulatory site on or near the $\mathrm{Cl}$ transport pathway. The structure of these compounds is close to that of GABA, well known for its stimulatory effect on $\mathrm{Cl}$ channels in central nervous system neurons (23). We reasoned that butyric acid, or one of the family of organic acids shown to inhibit $\mathrm{Cl}$ self-exchange, might be interacting with a GABA receptor. As shown in Table IV, $10 \mathrm{mM}$ GABA had no effect on $\mathrm{K}_{\mathrm{C}}$. This result makes it unlikely that there is a GABA receptor regulating this $\mathrm{Cl}$ transport pathway. Parenthetically, it is of interest to note that the addition of an amino group on the molecule eliminates the inhibitory effect of the parent organic acid. It is possible that the most important factor in this inactivation is the greatly lower lipid solubility of GABA compared to butyric acid. 
Effect of MAPTAM and cyanide on $K_{C l}$. We examined two possible mechanisms of action of organic acids that might involve alterations in intracellular environment. One possibility is that intracellular ionized $\mathrm{Ca}^{2+}$ was reduced. The reduction could be owing to the well-known effect of these compounds to bind $\mathrm{Ca}^{2+}(24)$, or their stimulation of mitochondrial $\mathrm{Ca}^{2+}$ uptake (25). To test this possibility, we added MAPTAM, a calcium chelator derived from EGTA (26) to the bath. If we assume that, at equilibrium, (a) the intracellular concentrations of MAPTAM and iso-butyrate are 0.1 and $25 \mathrm{mM}$, respectively, and $(b)$ the ratio of MAPTAM/iso-butyrate affinity constants for calcium is $10,000: 1(24,26)$, then MAPTAM would be predicted to chelate significantly more intracellular calcium than iso-butyrate. As shown in Table IV, $100 \mu \mathrm{M}$ MAPTAM (dissolved in dimethyl sulfoxide) had no effect on $\mathrm{K}_{\mathrm{Cl}}$. Therefore, it is unlikely that the effect of organic acids on $\mathrm{Cl}$ self exchange is mediated by a reduction in intracellular levels of ionized calcium.

We also considered the possibility that organic acids might inhibit $\mathrm{Cl}$ self exchange by altering cellular metabolism, for example by undergoing intramitochrondrial $\beta$-oxidation to acetyl-CoA (27). To determine whether $\mathrm{Cl}$ self-exchange is linked to metabolism, we tested the effect of cyanide on $\mathrm{K}_{\mathrm{Cl}}$. Cyanide blocks the reduction of oxygen catalyzed by cytochrome $\mathrm{aa}_{3}$ in mitochondria (28). Electrolyte transport dependent on ATP hydrolysis would be inhibited by cyanide. Table IV shows that $1 \mathrm{mM} \mathrm{NaCN}$ reduced $\mathrm{K}_{\mathrm{Cl}}$ from $376.2 \pm 55.1$ to $299.9 \pm 46.0 \mathrm{~nm} / \mathrm{s}\left(\Delta \mathrm{K}_{\mathrm{Cl}}=-76.4 \pm 15.0 \mathrm{~nm} / \mathrm{s}, P\right.$ $<0.01$ ). This result implies that a small fraction of $\mathrm{Cl}$ self-exchange is dependent on intact mitochondrial function. However, the fact that $\mathrm{K}_{\mathrm{C}}$ is reduced by both cyanide and by organic acids makes it unlikely that stimulation of cellular metabolism plays a major role in the inhibition of $\mathrm{Cl}$ self-exchange by organic acids.

Sidedness of iso-butyrate effect on $K_{C l}$. The results described above were obtained in experiments that examined the effects of organic acids on $\mathrm{Cl}$ self-exchange from the bath (basolateral) side. As previously described (1), it appears that transcellular $\mathrm{Cl}$ movement in the rabbit CCT intercalated cell occurs via an apical electroneutral entry step in series with a basolateral conductive pathway. Because of this polarity of $\mathrm{Cl}$ transport components, we examined the effects of organic acids on $\mathrm{Cl}$ self-exchange from the luminal side and compared lumen and bath effects on $\mathrm{Cl}$ self-exchange using $25 \mathrm{mM}$ isobutyrate. As shown in Fig. 5, using rapid perfusion rates and bath collections to measure $\mathrm{K}_{\mathrm{Cl}}, 25 \mathrm{mM}$ bath iso-butyrate reduced $\mathrm{Cl}$ self-exchange by $85 \%$, whereas $25 \mathrm{mM}$ lumen isobutyrate reduced $\mathrm{Cl}$ self exchange by only $22 \%(P<0.001)$. One possible reason for this difference in potency might be that the iso-butyrate concentration decayed axially along the tubule length owing to efflux into the bath. To examine this possibility, we measured counts of $\left[{ }^{14} \mathrm{C}\right]$ iso-butyrate in perfusates and in collected fluid at rapid perfusion rates; they were $20,931 \pm 103$ and $20,778 \pm 106 \mathrm{cpm}$, respectively. These results indicate that axial changes in lumen iso-butyrate concentration cannot account for the sidedness of the compound's effect on $\mathrm{K}_{\mathrm{C}}$. The preferential inhibition from the basolateral side strongly suggests, but does not prove, an effect on the basolateral membrane.

We also calculated the lumen-to-bath rate coefficient for $\left[{ }^{14} \mathrm{C}\right]$ iso-butyrate (measured simultaneously by bath and CVP collections) using the calculated iso-butyrate concentration of

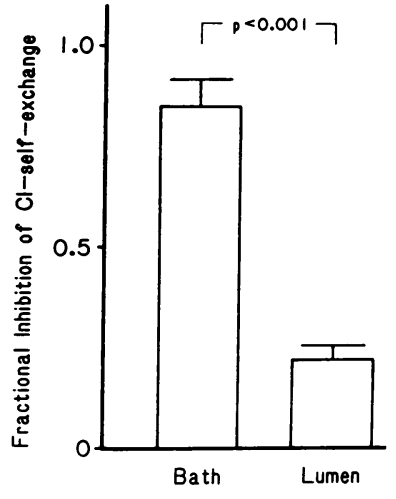

Figure 5. Fractional inhibition of $\mathrm{Cl}$ self-exchange by $25 \mathrm{mM}$ isobutyrate from bath and from lumen. Results were obtained in a paired, randomized fashion. $P$ $<0.001 . n=6$.

$24.92 \mathrm{mM}$. The butyrate rate coefficient was $41.8 \pm 3.4 \mathrm{~nm} / \mathrm{s}(n$ $=5$ ).

Effect of bath iso-butyrate on transepithelial conductance and $R b$ flux. We next tested the hypothesis that organic acids have their effect on $\mathrm{Cl}$ self-exchange by some action on a conductive pathway. We have previously modeled $\mathrm{Cl}$ transport as occurring via the $\beta$-intercalated cell (1). As modeled, this cell has no apical ion conductive pathways $(29,30)$, and thus changes in the basolateral $\mathrm{Cl}$ conductance are "invisible" to transepithelial conductance determinations. The principal cell also contains a $\mathrm{Cl}$ conductance at the basolateral membrane (31) and, in contrast to the $\beta$-intercalated cell, changes in this $\mathrm{Cl}$ conductance can be determined by transepithelial conductance measurements because the apical membrane of this cell type is conductive $(29,32)$. In Hepes-buffered solutions, and in the presence of lumen amiloride, $G_{\mathrm{T}}$ represents two conductances in series in principal cells: an apical $\mathrm{K}$ conductance and basolateral $\mathrm{K}$ and $\mathrm{Cl}$ conductances (31). An agent lowering basolateral membrane conductance could do so by lowering either the basolateral $\mathrm{K}$ and/or $\mathrm{Cl}$ conductances. Although $G_{\mathrm{T}}$ measurements alone cannot distinguish between these possibilities, it is possible to assess relative effects of an agent on these two ion pathways by comparing its effects on $G_{\mathrm{T}}$ and the lumen-to-bath ${ }^{86} \mathrm{Rb}$ rate coefficient $\left(\mathrm{K}_{\mathrm{Rb}}\right)$. Maneuvers that reduce $G_{\mathrm{T}}$ but have no effect on $\mathrm{K}_{\mathrm{Rb}}$ most likely are reducing the basolateral $\mathrm{Cl}$ conductance. We have used a similar construct to deduce the effect of $\mathrm{Cl}$ channel blockers on the principal and intercalated cell (9).

The effect of $25 \mathrm{mM}$ bath iso-butyrate on $G_{\mathrm{T}}$ is displayed in Fig. 6. Iso-butyrate reversibly reduced $G_{\mathrm{T}}$ from $9.3 \pm 1.7$ to $6.5 \pm 1.3 \mathrm{mS} \mathrm{cm}^{-2}(P<0.005)$. Recovery $G_{\mathrm{T}}$ was $9.1 \pm 1.6 \mathrm{mS}$ $\mathrm{cm}^{-2}$. These changes in $G_{\mathrm{T}}$ were maximal within $1 \mathrm{~min}$, were constant during the exposure, and were reversed within $5 \mathrm{~min}$ of washout. In contrast, Fig. 7 shows that $25 \mathrm{mM}$ bath iso-butyrate did not reduce but, in fact, increased $\mathrm{K}_{\mathrm{Rb}}$ from $70.2 \pm 11.8$ to $80.5 \pm 10.1 \mathrm{~nm} / \mathrm{s}\left(\Delta \mathrm{K}_{\mathrm{Rb}}=10.3 \pm 2.2 \mathrm{~nm} / \mathrm{s}, P\right.$ $<0.001$ ). Although we are unable to explain this increase, this result makes it unlikely that iso-butyrate reduced $\mathrm{K}$ conductances. Rather, $25 \mathrm{mM}$ bath iso-butyrate probably reduced the principal cell basolateral $\mathrm{Cl}$ conductance. By analogy, it seems likely that organic acids reduce $\mathrm{Cl}$ tracer flux through $\beta$-type intercalated cells by a similar inhibition of the basolateral $\mathrm{Cl}$ conductance in that cell.

\section{Discussion}

The present results demonstrate that organic acids inhibit $\mathrm{Cl}$ transport in the rabbit CCT. More potent when applied to the 


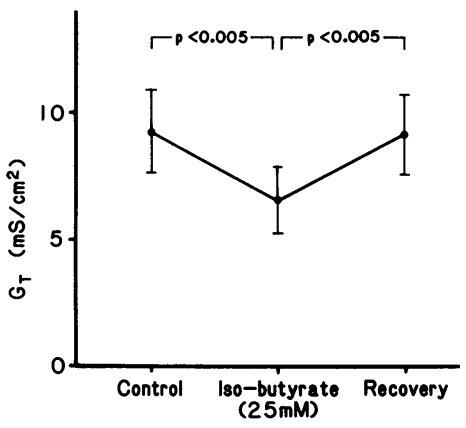

Figure 6. Effect of $25 \mathrm{mM}$ bath iso-butyrate on transepithelial conductance $\left(G_{\mathrm{T}}\right)$. Mean paired difference $2.7 \pm 0.4 \mathrm{mS} / \mathrm{cm}^{2}$.

basolateral rather than the apical membrane, the inhibition does not appear to be related to changes in cell metabolism, cytosolic calcium concentration, or the $\mathrm{pKa}$ of the organic acids. Rather, the inhibition correlates well with the chloroform/water partition coefficients of the acids and with the concentration of the protonated form. Thus, the inhibition is probably mediated by the undissociated, lipid-soluble form of the acids. Conductance measurements and measurements of $\mathrm{Rb}$ flux are consistent with inhibition of a basolateral $\mathrm{Cl}$ conductance on principal cells.

As recently reviewed (1), the majority of transcellular $\mathrm{Cl}$ transport by the rabbit CCT is mediated by the $\beta$-type intercalated cell. This cell contains an apical membrane anion exchanger. Chloride is brought into the cell electroneutrally in exchange for a secreted $\mathrm{HCO}_{3}$. In an alternative (and more frequent) mode of operation, one $\mathrm{Cl}$ is exchanged for another, a process termed self-exchange that effects no net flux and performs no work. $\mathrm{Cl}$ tracer brought into the cell at the apical membrane crosses the basolateral membrane via a $\mathrm{Cl}$ channel (9). If exogenous $\mathrm{HCO}_{3}$ and $\mathrm{CO}_{2}$ are omitted from the perfusion and bathing solutions, the exchange process is constrained to function in a $\mathrm{Cl}$ self-exchange mode. The $\mathrm{Cl}$ self-exchange mode represents a convenient and sensitive way to study the combined processes of apical anion exchange in series with basolateral conductive $\mathrm{Cl}$ exit.

Transport of Iso-butyrate. Because organic anions can be transported on anion exchangers in various epithelia $(5-8,13$, 14), we postulated that the same might hold true in CCT. Such was not the case. We will consider first the data bearing on whether iso-butyrate is transported out of the lumen via the $\beta$-intercalated cell apical anion exchanger. From previous ex-

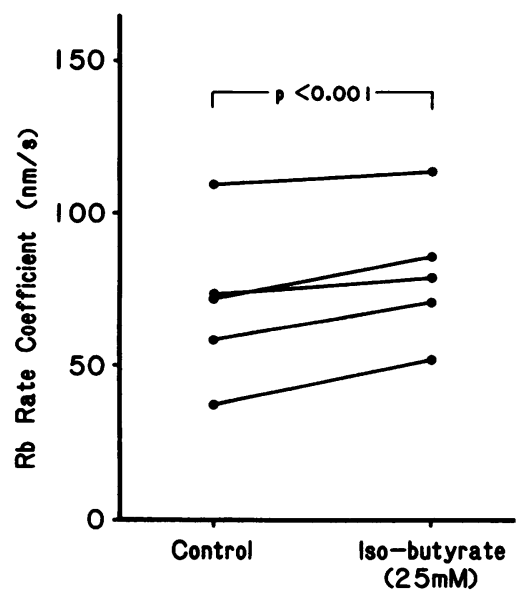

Figure 7. Effect of 25 $\mathrm{mM}$ bath iso-butyrate on the lumen-to-bath ${ }^{86} \mathrm{Rb}$ rate coefficient. Mean paired increase was $10.3 \pm 2.2 \mathrm{~nm} \mathrm{~s}^{-1}$. periments $(2,9)$ and the 0 bath $\mathrm{Cl}$ experiments in Table I, we know that the paracellular lumen-to-bath $\mathrm{Cl}$ (diffusive) flux (expressed as a rate coefficient) is $\sim 30 \mathrm{~nm} \mathrm{~s}^{-1}$. The mobility of the iso-butyrate anion is 0.43 that of $\mathrm{Cl}$ (33). Therefore, assuming the tight junction does not select organic over inorganic anions, one would predict a paracellular (diffusional) iso-butyrate anion permeation of $\sim 0.43 \times 30=13 \mathrm{~nm} \mathrm{~s}^{-1}$. We measured the total lumen-to-bath iso-butyrate anion rate coefficient as $41.8 \pm 3.4 \mathrm{~nm} \mathrm{~s}^{-1}$. Subtracting the predicted diffusive component of $13 \mathrm{~nm} \mathrm{~s}^{-1}$, we are left with a predicted cellular rate coefficient of $\sim 29 \mathrm{~nm} \mathrm{~s}^{-1}$. This low value stands in contrast to the typical $\mathrm{Cl}$ rate coefficient of $100-400 \mathrm{~nm} \mathrm{~s}^{-1}$ (2, 3, 9, and Tables I, III, and IV, and Fig. 1), suggesting that very little transport of iso-butyrate as the anion takes place via the exchanger.

If this "cellular" butyrate rate coefficient is recalculated using the concentration of iso-butyric acid $(70 \mu \mathrm{M})$ instead of the total iso-butyrate concentration, the rate coefficient is $10.2 \pm 1.2 \mu \mathrm{m} \mathrm{s}^{-1}{ }^{2}$ This permeability coefficient is indistinguishable from the butanol permeability in CCT of $12.2 \pm 0.5$ $\mu \mathrm{m} \mathrm{s}^{-1}$ reported by Schafer and Andreoli (34). Thus, assuming that iso-butyrate and iso-butyric acid permeation occur via both ionic and nonionic diffusion, and assuming that butanol permeability is a reasonable approximation of (undissociated) butyric acid permeability, then all of the predicted "cellular" iso-butyrate flux of $28.6 \mathrm{~nm} \mathrm{~s}^{-1}$ can be theoretically accommodated by absorption as the undissociated form. Carriermediated transport of iso-butyrate anion by the anion transport pathway must therefore be close to zero.

Mechanism of inhibition. The mechanism(s) involved in the inhibition of $\mathrm{Cl}$ transport by organic acids cannot be deduced completely from the present experiments, but there are some clues. The inhibition is not owing to competition by the organic anions for $\mathrm{Cl}$ transport as is the case for the monocarboxylate transporter of the proximal tubule $(5,6,35)$ : in the proximal tubule, organic acids are themselves transported, their inhibitory potency on lactate transport is inversely related to size, and their effect is strongly related to the charge density of the carboxyl group. In contrast, organic acids in the CCT are not themselves transported, their inhibitory potency is more directly related to size, and their effect is mediated by the undissociated moiety.

Because organic acids tend to lower intracellular $\mathrm{pH}$ by virtue of their low pKa and by their ability to enter the cell by non-ionic diffusion, one might postulate that these agents alter $\mathrm{Cl}$ transport via a cell $\mathrm{pH}$ effect. In this regard, it is important to recognize that the final cell $\mathrm{pH}$ in the presence of continuous exposure to external organic acids is a function of the balance between the rate of the cell's proton-extruding mechanisms and the extrusion mechanisms for the associated anion. In most cells, the steady state cell $\mathrm{pH}$ is usually more acidic in the presence of an organic acid (36). It is therefore conceivable that a lowering of cell $\mathrm{pH}$ may have caused the inhibition of $\mathrm{Cl}$ transport reported here. We have not yet directly measured changes in cell $\mathrm{pH}$ in CCT under these conditions. However, we have found in separate studies that addition of exogenous $\mathrm{CO}_{2}$, a maneuver that consistently lowers cell $\mathrm{pH}$ in other cells (36), actually stimulates CCT Cl self-exchange (3; and unpub-

2. This rate coefficient is calculated assuming an iso-butyric acid concentration of $70 \mu \mathrm{M}$ which obtains at $\mathrm{pH} 7.4$ and an iso-butyrate concentration of $25 \mathrm{mM}$. 
lished observations). Thus, it seems unlikely that a lowering of cell $\mathrm{pH}$ by organic acids is the sole mechanism by which these agents inhibit $\mathrm{Cl}$ transport.

Another possible mechanism of inhibition by organic acids, especially butyrate, is via alteration of nuclear function. Of particular relevance to the CCT, butyrate has been shown to partially inhibit the aldosterone-induced increase in $\mathrm{Na}$ transport by the toad urinary bladder (37). Such an effect is thought to involve acetylation of histones and alteration of differentiation $(38,39)$. These effects require hours to days to develop, whereas the reduction of $\mathrm{CCT} \mathrm{Cl}$ transport occurs in minutes or seconds. Therefore, it seems unlikely that these mechanisms play a role in altering $\mathrm{Cl}$ transport in the present experiments.

Interaction with membrane lipids. The effects of lipid soluble compounds on membrane transport processes have been the subject of considerable investigation. For purposes of this discussion, we will divide their effects into three general categories: $(a)$ interaction with, and disruption of the lipid bilayer, (b) alteration of membrane surface charge, and (c) specific interaction of a portion of the inhibitor molecule with a charged site in the transport protein in combination with an interaction of the hydrophobic region of the inhibitor molecule with the lipid domain.

The first of these three mechanisms is best exemplified by the anesthetics. Anesthetics are thought to produce their effects on ionic currents in nerve membranes by disrupting the lipid organization $(40,41)$. Although the specific nature of this interaction is probably complex, the general effect has been attributed to changes in membrane fluidity and/or the membrane dipole potential (42-44). This class of interaction is characteristic of many kinds of lipid soluble substances such as alkanes, alcohols, unsaturated hydrocarbons, undissociated organic acids, and nonpolar compounds $(11,41,42,45)$. Of relevance to the present data, studies of organic compounds in nerve membranes demonstrate that the $\mathrm{IC}_{50}$ of the undissociated acid was approximately the same as the $\mathrm{IC}_{50}$ of the corresponding alcohol (42). This mechanism is thus not a likely explanation for our results since $n$-butanol in substantially higher concentrations than the undissociated butyric acid had no effect on $\mathrm{Cl}$ transport (Table IV).

With regard to the second mechanism, alteration in surface charge has been postulated by Caffier et al. (10) to explain the reduction in $\mathrm{Cl}$ conductance and increase in cation conductance produced by octanoate in frog skeletal muscle. They postulated that this effect was owing to an increase in surface charge resulting from the insertion of the non-polar tail of the organic acid into the lipid domain. Although we are not certain whether or not that explanation obtains for frog muscle, it seems unlikely in the CCT. If surface charge were the major factor, titration of the charges by lowering the $\mathrm{pH}$ should have mitigated the inhibitory effect, rather than enhance it as was observed (Table III).

The last putative mechanism to be considered is that a charged part of the inhibitor molecule interacts with a charged site on the transport protein, and that a hydrophobic part of the inhibitor molecule interacts with the lipid domain of the membrane. This particular hypothesis appears to have the most merit in explaining our CCT data. Our data indicate that a wide variety of organic acids can interact specifically with $\mathrm{Cl}$ conductive pathways in these epithelial cells. There appear to be two requirements: a carboxyl group and a hydrophobic domain. These organic acids thus behave in a fashion similar to a large number of organic acids derived from anthracene and diphenylamines $(9,12)$ whose potency has been attributed to the presence both of a carboxyl group and of a hydrophobic region.

The site of action of these organic acids on $\mathrm{Cl}$ self-exchange cannot be deduced with certainty. However, we suspect that the majority of the inhibition is occurring at the basolateral $\mathrm{Cl}$ channel rather than the apical exchanger for the following reasons: ( $a$ ) the effect is more pronounced from the basolateral side than the apical side (Fig. 5); (b) the reduction of the transepithelial conductance (Figs. 6 and 7) is probably an effect on a $\mathrm{Cl}$ conductive pathway (albeit on another cell type); (c) the effect of these organic acids on the CCT is the same as the effect of other agents known to inhibit $\mathrm{Cl}$ conductive pathways in other cells $(9,12)$; and $(d)$ there is a precedent for organic acid inhibition of $\mathrm{Cl}$ channels in muscle cells (10). The clear conclusion in this regard must await additional experiments. We cannot exclude the possibility that these agents affect the electrically silent anion exchanger and note that other inhibitors of $\mathrm{Cl}$ channels can inhibit electrically silent pathways $(12,46)$.

The physiologic importance of the inhibition of $\mathrm{Cl}$ conductive pathways by organic acids is probably minimal. We note that lactate, the acid most likely to be available in millimolar concentrations, has only a small effect on $\mathrm{Cl}$ transport (Table II). The others tested are less likely to be present in such concentrations. The inhibition described herein, then, may prove most valuable to our understanding of the interaction of $\mathrm{Cl}$ channel inhibitors with the $\mathrm{Cl}$ channel. Additionally, the discovery that butyrate can inhibit $\mathrm{Cl}$ conductances suggests that the mechanism of longterm (days) butyrate effects on cell function may need reexamination. Although histone acetylation, etc., clearly occurs $(38,39)$, it is possible that some of the previously described effects on intact cells result from a primary blockade of anion channels.

\section{Acknowledgments}

We thank Sydney Harned and Peggy Meyerrose for secretarial assistance and Ivan Lee for technical assistance.

Supported by National Institutes of Health grants DK-38095, DK-01343, and DK-25231 and by a Merit Review Grant from the Veterans Administration (to Dr. Schuster). Dr. Matsuzaki is a fellow of the National Kidney Foundation. Dr. Stokes is an Established Investigator of the American Heart Association. Dr. Schuster is the recipient of National Institutes of Health Clinical Investigator Award DK-01343.

\section{References}

1. Schuster, V. L., and J. B. Stokes. 1987. Cl transport by the cortical and outer medullary collecting duct. Am. J. Physiol. 253(Renal Fluid Electrolyte Physiol. 22):F203-F212.

2. Tago, K., V. L. Schuster, and J. B. Stokes. 1986. Regulation of chloride self exchange by cAMP in cortical collecting tubule. Am. J. Physiol. 251(Renal Fluid Electrolyte Physiol. 20):F40-F48.

3. Tago, K., V. L. Schuster, and J. B. Stokes. 1986. Stimulation of chloride transport by $\mathrm{HCO}_{3}-\mathrm{CO}_{2}$ in rabbit cortical collecting tubule. Am. J. Physiol. 251(Renal Fluid Electrolyte Physiol. 20):F49-F56.

4. Aubert, L., and R. Motais. 1975. Molecular features of organic anion permeability in ox red blood cell. J. Physiol. 246:159-179.

5. Ullrich, K. J., G. Rumrich, and S. Kloss. 1982. Reabsorption of monocarboxylic acids in the proximal tubule of the rat kidney. II. Specificity for aliphatic compounds. Pfluegers Arch. 395:220-226. 
6. Ullrich, K. J., G. Rumrich, S. Kloss, and H. Fasold. 1982. Reabsorption of monocarboxylic acids in the proximal tubules of the rat kidney. III. Specificity for aromatic compounds. Pfluegers Arch. 395:227-231.

7. Petersen, K., J. R. Wood, G. Schulze, and K. Heintze. 1981. Stimulation of gallbladder fluid and electrolyte absorption by butyrate. J. Membr. Biol. 62:183-193.

8. Hollander, D., E. M. Gerard, and C. A. R. Boyd. 1986. Transport of butyric acid in vascularly perfused anuran small intestine: importance of pH and anion transport. Am. J. Physiol. 250(Gastrointest. Liver Physiol. 13):G469-G474.

9. Tago, K., D. H. Warden, V. L. Schuster, and J. B. Stokes. 1986. Effects of inhibitors of $\mathrm{Cl}$ conductance on $\mathrm{Cl}$ self-exchange in the rabbit cortical collecting tubule. Am. J. Physiol. 251(Renal Fluid Electrolyte Physiol. 20):F1009-F1017.

10. Caffier, G., F. Kossler, and G. Kuchler. 1980. The influence of free fatty acids on functional properties of isolated skeletal muscles. Octanoate action on membrane resistance. Pfluegers Arch. 383:87-89.

11. Takenaka, T., H. Horie, and H. Hori. 1987. Effects of acids on membrane currents in the squid giant axon. J. Membr. Biol. 95:113120.

12. Wangemann, P., M. Wittner, A. DiStefano, H. C. Englert, H. J. Lang, E. Schlatter, and R. Greger. 1986. $\mathrm{Cl}^{-}$-channel blockers in the thick ascending limb of the loop of Henle. Structure activity relationship. Pfluegers Arch. 407(Suppl. 2):S128-S141.

13. Karniski, L. P., and P. S. Aronson. 1985. Chloride/formate exchange with formic acid recycling: a mechanism of active chloride transport across epithelial membranes. Proc. Natl. Acad. Sci. USA. 82:6362-6365.

14. Schild, L., G. Giebisch, L. P. Karniski, and P. S. Aronson. 1987. Effect of formate on volume reabsorption in the rabbit proximal tubule. J. Clin. Invest. 79:32-38.

15. Alpern, R. J. 1987. Apical membrane chloride/base exchange in the rat proximal convoluted tubule. J. Clin. Invest. 79:1026-1030.

16. Burg, M. D., J. Grantham, M. Abramow, and J. Orloff. 1966. Preparation and study of fragments of single rabbit nephrons. Am. J. Physiol. 210:1293-1298.

17. Christoffersen, G. R. J., and C. H. Skibsted. 1975. Calcium ion activity in physiological salt solutions: influence of anions substituted for chloride. Comp. Biochem. Physiol. 52A:317-322.

18. Stokes, J. B., and J. P. Kokko. 1977. Inhibition of sodium transport by prostaglandin $E_{2}$ across the isolated, perfused rabbit collecting tubule. J. Clin. Invest. 59:1099-1104.

19. Stokes, J. B., M. J. Ingram, A. D. Williams, and D. Ingram. 1981. Heterogeneity of the rabbit collecting tubule: localization of mineralocorticoid hormone action to the cortical portion. Kidney Int. 20:340-347.

20. Jackson, M. J., A. M. Williamson, W. A. Dombrowski, and D. E. Garner. 1978. Intestinal transport of weak electrolytes. Determinants of influx at the luminal surface. J. Gen. Physiol. 71:301-327.

21. Dean, J. A. 1979. Lange's Handbook of Chemistry. McGrawHill Book Co., New York. 12th Ed. 5-17-5-41.

22. Wright, E. M., and J. M. Diamond. 1969. Patterns of non-electrolyte permeability. Proc. Roy. Soc. Lond. (Ser. B). 172:227-271.

23. Mathers, D. A., and J. L. Barker. 1982. Chemically induced ion channels in nerve cell membranes. Int. Rev. Neurobiol. 23:1-34.

24. Colman-Porter, C. A., and C. B. Monk. 1952. Dissociation constants of the alkaline-earth salts of some monocarboxylic acids. $J$. Chem. Soc. 4363-4373.

25. Lehninger, A. L., E. Carafoli, and C. S. Rossi. 1967. Energylinked ion movements in mitochondrial systems. Adv. Enzymol. 29:259-320.

26. Tsien, R. Y. 1980. New calcium indicators and buffers with high selectivity against magnesium and protons: design, synthesis and properties of prototype structures. Biochemistry. 19:2396-2404.
27. Snyder, F. 1977. Lipid Metabolism in Mammals. Plenum Press, New York. Vol. 1. 2-4.

28. Lehninger, A. L. 1982. Principles of Biochemistry. Worth Publishers, Inc., New York. 483.

29. Koeppen, B. M., B. A. Biagi, and G. H. Giebisch. 1983. Intracellular microelectrode characterization of the rabbit cortical collecting duct. Am. J. Physiol. 244(Renal Fluid Electrolyte Physiol. 13):F35-F47.

30. Sansom, S. C., S. Muto, and G. Giebisch. 1986. Microelectrode assessment of conductive properties of "minority cells" of the rabbit cortical collecting duct. Fed. Proc. 45:541.

31. Sansom, S. C., E. J. Weinman, and R. G. O'Neil. 1984. Microelectrode assessment of chloride conductive properties of cortical collecting duct. Am. J. Physiol. 247(Renal Fluid Electrolyte Physiol. 16):F291-F302.

32. O'Neil, R. G., and S. C. Sansom. 1984. Electrophysiological properties of cellular and paracellular pathways of the rabbit cortical collecting duct. J. Membr. Biol. 82:281-295.

33. Dean, J. A. 1979. Lange's Handbook of Chemistry. McGrawHill Book Co., New York. 12th Ed. 6-35.

34. Schafer, J. A., and T. E. Andreoli. 1972. Cellular constraints to diffusion. The effect of antidiuretic hormone on water flows in isolated mammalian collecting tubules. J. Clin. Invest. 51:1264-1278.

35. Nord, E. P., S. H. Wright, I. Kippen, and E. M. Wright. 1983. Specificity of the $\mathrm{Na}^{+}$-dependent monocarboxylic acid transport pathway in rabbit renal brush border membranes. J. Membr. Biol. 72:213221.

36. Boron, W. F. 1985. Control of intracellular pH. In The Kidney: Physiology and Pathophysiology. D. W. Seldin and G. Giebisch, editors. Raven Press, NY.

37. Rossier, B. C., A. Truscello, and K. Geering. 1982. Antimineralocorticoid effect of sodium butyrate and triiodothyronine: evidence for two pathways in the action of aldosterone on $\mathrm{Na}^{+}$transport in the toad bladder. In Biochemistry of Kidney Functions. F. Morel, editor. Elsevier Biomedical Press, New York. 225-232.

38. Buffa, L. C., R. J. Gruss, and V. G. Allfrey. 1981. Manifold effects of sodium butyrate on nuclear function. Selective and reversible inhibition of phosphorylation of histones $\mathrm{HI}$ and $\mathrm{H} 2 \mathrm{~A}$ and impaired methylation of lysine and arginine residues in nuclear protein fractions. J. Biol. Chem. 256:9612-9621.

39. Kruh, J. 1982. Effects of sodium butyrate, a new pharmacological agent, on cells in culture. Mol. Cell. Biochem. 42:65-82.

40. Bean, B. P., P. Shrager, and D. A. Goldstein. 1981. Modification of sodium and potassium channel gating kinetics by ether and halothane. J. Gen. Physiol. 77:233-253.

41. Haydon, D. A., and B. W. Urban. 1983. The effects of some inhalation anesthetics on the sodium current of the giant squid axon. $J$. Physiol. 341:429-439.

42. Elliot, J. R., D. A. Haydon, and B. M. Hendry. 1984. The asymmetrical effects of some ionized n-octyl derivatives on the sodium currents of the giant axon of Loligo forbesi. J. Physiol. 350:429-445.

43. Takenaka, T., H. Horie, and Y. Kawasaki. 1983. Effect of fatty acids on the membrane fluidity of cultured chick dorsal root ganglion measured by fluorescence photobleaching recovery. J. Neurobiol. 14:457-461.

44. Reyes, J., and R. Lattorre. 1979. Effect of the anesthetics benzylalcohol and chloroform on bilayers made from monolayers. Biophys. J. 28:259-280.

45. Haydon, D. A., and B. W. Urban. 1983. The action of alcohols and other non-ionic surface active substances on the sodium current of the giant squid axon. J. Physiol. 341:411-427.

46. Reuss, L., J. L. Costantin, and J. E. Bazile. 1987. Diphenylamine-2-carboxylate blocks $\mathrm{Cl}-\mathrm{HCO}_{3}$ exchange in Necturus gallbladder epithelium. Am. J. Physiol. 253(Cell Physiol. 22):C79-C89. 